\title{
A Novel Description Method for Track Irregularity Evolution
}

\author{
Peng Xu", Ph.D. \\ Rengkui Liu, Associate Professor \\ Futian Wang, Associate Professor \\ Quanxin Sun, Professor \\ State Key Laboratory of Rail Traffic Control \& Safety, Beijing Jiaotong University, No.3 Shang Yuan Cun \\ Haidian District, Beijing 100044, China \\ Hualiang (Harry) Teng, Associate Professor \\ Department of Civil and Environmental Engineering, University of Nevada, Las Vegas, 4505 Maryland Parkway, Box \\ 454015 \\ Las Vegas, NV 89154-4015, USA
}

\begin{abstract}
Track Irregularity has a significant influence on the safety of train operation. Due to the fact that the extremely large number of factors affect track irregularity, it is challenging to find a concise yet effective mathematical method to describe the evolution of track irregularity. In this paper, inspection data generated by GJ-4 track inspection cars from Jinan Railway Bureau in China were analyzed to identify the characteristics of track irregularity changes common to different mileage points. Based on these characteristics, a multi-stage linear fitting model to describe the pattern of track irregularity evolution over time was developed. The availability of new inspection data will make the model revise itself. In this sense, the model is a machine learning model. Finally, inspection data from the Beijing-Shanghai Railway Line (Jing-Hu Line) were used to verify the model.
\end{abstract}

Key words: Railway; Track Irregularity; Inspection Data; Fitting Mode; Machine Learning Model

\section{Introduction}

Traffic accidents have long been social-economical problem which has caused increasing concern to the public worldwide. ${ }^{1}$ According to statistics on train accidents by Office of Safety of US Federal Railroad Administration, 542933 people were injured or killed by railway accidents mainly caused by railway track from January 1975 to May 2011. ${ }^{2}$

The roles of the railway track are to guide the vehicle or locomotive traveling, endure the comprehensive effect of contributing environmental variables and loads from wheels, distribute wheel loads to roadbed, bridges or tunnels, provide a smooth trajectory for wheel running, keep operation costs, travel safety and passenger comfort within a accepted range and roadbed in a good condition. $^{3,4,5}$ Track condition includes two categories: track geometry condition and track structure condition. ${ }^{6}$ Track geometry condition plays a significant role in ensuring train travel safety and passenger comfort ${ }^{7}$ and is usually determined by several geometry parameters 5 . These parameters consist of projections of rails in the horizontal, longitudinal and vertical planes and include gauge, $G$, and cross level, $C L$, in the horizontal plan,

* Corresponding author: suepen_aili@126.com 
longitudinal level, $L L$, in the vertical plan, alignment, $A$, in the longitudinal plane, and twist, $T$, for measuring uneven running surface. ${ }^{8}$ In theory, values of these five parameters including gauge, cross level, longitudinal level, alignment and twist are $G_{0}$ which is the designed gauge and in most countries is $1435 \mathrm{~mm}$, $0 \mathrm{~mm}, 0 \mathrm{~mm}, 0 \mathrm{~mm}$ and $0 \mathrm{~mm} / \mathrm{m}$ for the straight track, respectively, and for the curved track are $G_{0}+G_{w}$ wherein $G_{w}$ is the designed widened gauge, $C L_{0}$ which is the designed super-elevation, $0 \mathrm{~mm}, 0 \mathrm{~mm}$ and $0 \mathrm{~mm} / \mathrm{m}$, respectively. Due to many reasons, ${ }^{3,9}$ however, the actual values of these parameters deviate from their theoretical ones. These deviations are usually referred to as track irregularity. ${ }^{5}$ The existence of track Irregularity makes the running trajectory of wheels unsmooth. The unsmooth trajectory will lead to vibrations of vehicles and locomotives and dynamic forces between wheels and rails. These vibrations of trains and dynamic forces of the wheel-rail interaction not only reduce train travelling safety and passenger comfort but also shorten life of track equipments, ${ }^{3,10}$ what is more, deteriorate track irregularity $^{3,11}$. According to 184 accident investigation reports published between October 2005 and June 2010 by Rail Accident Investigation Branch of UK, there are 58 derailments and 24 of them are resulted from bad track irregularity. ${ }^{12}$

The traditional regimen and methods of track maintenance can no longer be adaptable to the policies currently implemented for railways in China which require "greatly increasing train weight, actively shortening running frequency and raising running speed as much as possible". ${ }^{13}$ It is therefore necessary to adopt track irregularity-based maintenance methods. The core of such a method is the preventive maintenance technique, which involves the formulation of maintenance plans based on actual track irregularity. This method for track maintenance is the same as the current trends in other equipment surveillance systems. ${ }^{14}$

In 2008, Jinan and Kunming railway bureaus signed a $R \& D$ project of railway maintenance safety production management information system, in which one of the important research areas is to scientifically evaluate and judge track irregularity based on historical track inspection data, with the authors' laboratory.

There have been some studies on the pattern of the changes in track irregularity. Refs. 15 and 16 have developed models to describe track irregularity changes along different sections of different railway lines as well as models to formulate maintenance plans which take safety risks and maintenance cost as the 2 objectives. Ref. 17 has applied fractal analysis to track geometry data and developed numerical indices for track condition assessment. An information system has also been developed which uses basic track databases to automatically diagnose track irregularity. ${ }^{18} \mathrm{~A}$ Reliability-Centered Maintenance (RCM) approach has been proposed and applied in the maintenance and repair of railway points. ${ }^{19}$ Kawaguchi et al. and Morimoto and Miwa at Railway Technical Research Institute in Japan have respectively developed degradation models which utilize standard deviations of track geometry measurements to predict standard deviations of track alignment and surface of $100 \mathrm{~m}$-long track sections. ${ }^{20}$ Employing stochastic process theory, Iyengar and Jaiswal have analyzed track surface measurements obtained from two railway lines in India and concluded that track surface can be modeled as a stationary Gaussian stochastic process. ${ }^{21}$ Alfelor et al. have built a track degradation database storing track gauge restraints and track geometry parameters measured with Gage Restraint Measurement System, traffic loads, environment, track structural characteristics, and developed a track degradation analysis program which can formulate a one-to-one relationship between track degradation and a contributing parameter by employing least square linear regression. ${ }^{22}$ As the authors of ref. 22 have pointed out that in the current stage no statistically significant track degradation models or relationships can be derived by using the existing information from the track degradation database. Chen et al. at China Academy of Railway Sciences have developed an integrated factor method (IFM) which utilizes the latest track waveform measurements to predict track irregularity parameter values for every mileage points. ${ }^{23}$ In order to make predictions, IFM divides a railway track into $200 \mathrm{~m}$-long unit sections, classifies unit sections into 17 categories, and supposes that unit sections in the same category have the same deterioration rate of track irregularity.

Different from these studies, the study presented in this paper analyzed the basic characteristics of track irregularity changes and based on these common characteristics developed a multi-stage framework that integrated linear regression models to estimate the deterioration of the track irregularity over time. In other words, our track irregularity prediction model is a 
characteristics-based and track inspection data-driven model.

The rest of the paper is organized as follows. We first introduce the data used for analyzing the common track irregularity evolution characteristics in Section 2. In Section 3 by analyzing the actual performance graphs of $27,384,000$ series, the common track irregularity characteristics are identified. In Section 4 based on the common characteristics a Multi-stage linear fitting model is developed for describing track irregularity evolution. Conclusions are drawn in Section 5.

\section{Data Preparation}

\subsection{Introduction to Waveform Data from GJ-4 Track Inspection Car}

Track inspection car is one of equipment often used to inspect railway track irregularity. ${ }^{5} \mathrm{Up}$ to 2007 , China railway had 3 types of track inspection car which consist of GJ-3, GJ-4 and GJ-5. ${ }^{24}$ After each inspection, track inspection car will generate two formats of data files, a MS Access database file and a binary data file, whose contents are used to assess track irregularity. ${ }^{25}$ The binary file stores track irregularity measurements at each sampling point along railway tracks, and the MS Access file stores statistical results of track irregularity measurements. Therefore, the binary file is usually referred to as the original or track waveform data file, and the MS Access file as the report data file.

Based on the original data generated by GJ-4 track inspection cars, this paper will conduct analysis and research on the pattern of changes in track irregularity.

(1) Inspection frequency requirements

The designed speed of GJ-4 track inspection car is $140 \mathrm{Km} / \mathrm{h}$. It is suitable for railway lines with an allowable speed under $160 \mathrm{Km} / \mathrm{h}$. These suitable lines include both the existing speed-raised railway lines and normal speed railway lines in China. Ref. 26 stipulates that main lines with an allowable speed between $120 \mathrm{Km} / \mathrm{h}$ and $200 \mathrm{Km} / \mathrm{h}$ must be inspected at least twice a month and main lines with an allowable speed under $120 \mathrm{Km} / \mathrm{h}$ must be inspected once a month.

(2) Sampling distance

GJ-4 track inspection car samples various irregularities at 4,000 points every $1 \mathrm{Km}$ of a railway line. In other words, the sampling distance is $0.25 \mathrm{~m}$.

(3) Items for inspection
GJ-4 waveform data includes 13 items, as shown in Table 1. The chord length of $10 \mathrm{~m}$ is used for the track surface and alignment measurement, and the length of $2.5 \mathrm{~m}$ for twist. During the inspection, these 13 measured items are stored in a binary format file.

Table 1 Inspection Items by GJ-4 Track Inspection Car

\begin{tabular}{llllll}
\hline Item & Unit & Item & Unit & Item & Unit \\
\hline Speed & $\mathrm{Km} / \mathrm{h}$ & Gauge & $\mathrm{mm}$ & Surface & $\mathrm{mm}$ \\
Mileage & $\mathrm{Km}$ & Cross level & $\mathrm{mm}$ & Alignment & $\mathrm{mm}$ \\
Twist & $\mathrm{mm}$ & Curvature & $\mathrm{Rad} / \mathrm{Km}$ & Super elevation & $\mathrm{mm}$ \\
Lateral acceleration & $\mathrm{g}$ & Vertical & $\mathrm{g}$ & ALD & $\mathrm{v}$ \\
& & acceleration & & & \\
Axle-box acceleration & $\mathrm{g}$ & & & & \\
\hline
\end{tabular}

\subsection{Standard for Dynamic Track Irregularity Management}

To ensure the safety and comfort of train operations, the railway authorities in China have divided the permissible dynamic track irregularity deviations into 4 tiers based on the allowable train running speed (Vas). The 4 tiers are denoted as Tier I, II, III and IV, respectively ${ }^{26}$. These tiers respectively stand for the control values for routine maintenance, for comfort level, for emergency supplementary repair, and for speed limit. The threshold values for each tier are given in Table 2.

Table 2 Standard for Dynamic Track Irregularity Management

\begin{tabular}{|c|c|c|c|c|c|}
\hline $\begin{array}{c}\text { Track } \\
\text { Irregularity } \\
\text { Items }\end{array}$ & Tier & Vas $\leq 120 \mathrm{Km} / \mathrm{h}$ & $\begin{array}{c}120 \mathrm{Km} / \mathrm{h}< \\
\text { Vas } \\
\leq 160 \mathrm{Km} / \mathrm{h}\end{array}$ & $\begin{array}{c}160 \mathrm{Km} / \mathrm{h}< \\
\text { Vas } \\
\leq 200 \mathrm{Km} / \mathrm{h}\end{array}$ & $\begin{array}{c}200 \mathrm{Km} / \mathrm{h} \leq \\
\text { Vas } \\
\leq 250 \mathrm{Km} / \mathrm{h}\end{array}$ \\
\hline \multirow{8}{*}{$\begin{array}{l}\text { Gauge } \\
(\mathrm{mm})\end{array}$} & \multirow{2}{*}{ I } & +8 & +6 & +4 & +4 \\
\hline & & -6 & -4 & -3 & -3 \\
\hline & \multirow{2}{*}{ II } & +12 & +10 & +8 & +6 \\
\hline & & -8 & -7 & -4 & -4 \\
\hline & \multirow{2}{*}{ III } & +20 & +15 & +12 & +8 \\
\hline & & -10 & -5 & -6 & -6 \\
\hline & \multirow{2}{*}{ IV } & +24 & +20 & +15 & +12 \\
\hline & & -12 & -10 & -8 & -8 \\
\hline \multirow{4}{*}{$\begin{array}{l}\text { Cross level } \\
(\mathrm{mm})\end{array}$} & I & 8 & 6 & 5 & 5 \\
\hline & II & 12 & 10 & 8 & 8 \\
\hline & III & 18 & 14 & 12 & 10 \\
\hline & IV & 22 & 18 & 14 & 13 \\
\hline \multirow{4}{*}{$\begin{array}{l}\text { Surface } \\
(\mathrm{mm})\end{array}$} & I & 8 & 6 & 5 & 5 \\
\hline & II & 12 & 10 & 8 & 8 \\
\hline & III & 20 & 15 & 12 & 11 \\
\hline & IV & 24 & 20 & 15 & 14 \\
\hline \multirow{4}{*}{$\begin{array}{l}\text { Alignment } \\
(\mathrm{mm})\end{array}$} & I & 8 & 5 & 5 & 5 \\
\hline & II & 10 & 8 & 7 & 7 \\
\hline & III & 16 & 12 & 10 & 8 \\
\hline & IV & 20 & 16 & 12 & 10 \\
\hline
\end{tabular}




\begin{tabular}{l|ccccc} 
& I & 8 & 5 & 4 & 4 \\
Twist & II & 10 & 8 & 6 & 6 \\
$(\mathrm{~mm})$ & III & 14 & 12 & 9 & 8 \\
& IV & 16 & 14 & 12 & 10 \\
\hline
\end{tabular}

\subsection{Waveform Data Obtained by GJ-4 Track Inspection Car from Jing-Hu Line}

Jing-Hu Line is a double track railway line. Before April 2007, the section of Jing-Hu Line administered by the Jinan Railway Bureau had an allowable speed of between $120 \mathrm{Km} / \mathrm{h}$ and $200 \mathrm{Km} / \mathrm{h}$. According to the rules as stated in 2.1, this railway line was inspected by GJ-4 Track Inspection Cars at least twice a month. The authors have gathered some of the GJ-4 waveform data from the Jinan section of Jing-Hu Line. All the data were sampled during the 2004-2006 period. The basic information on the data is shown in Table 3.

Table 3 Gathered Waveform Data

\begin{tabular}{ccccc}
\hline $\begin{array}{c}\text { Direction } \\
\text { of Travel }\end{array}$ & $\begin{array}{c}\text { Mileage } \\
\text { Range }\end{array}$ & Time Span & $\begin{array}{c}\text { Number of } \\
\text { Times }\end{array}$ & $\begin{array}{c}\text { Data } \\
\text { Size } \\
(\mathrm{GB})\end{array}$ \\
\hline $\begin{array}{c}\text { Up going } \\
\text { Down } \\
\text { going }\end{array}$ & $2327---238$ & $2004.9---2006.11$ & 44 & 42.9 \\
\hline
\end{tabular}

\section{Characteristics of Changes in Railway Track Irregularity}

Based on the inspection data collected in this study, the study analyzed the processes of temporal changes of track irregularity state at different locations. Let $\left\{X\left(t_{i}\right)\right\}$ denote the inspected values of a track irregularity at a certain inspecting location. The term $\left\{M\left(t_{i}\right)\right\}$ represents maintenance treatments performed at time $t_{i} .\left\{S\left(t_{i}\right)\right\}$ is the number of days when an inspection was performed since the last maintenance treatment. Given that inspection is performed in $0.25 \mathrm{~m}$ distance interval and there were seven track irregularities (gauge, cross level, left alignment, right alignment, left surface, right surface and twist) measured, there were 27,384,000 data items collected for $\left\{X\left(t_{i}\right)\right\}$, which is significantly large. A program was written in this study to plot the performance graph of the track irregularity based on $\left\{X\left(t_{i}\right)\right\}$ and the corresponding thresholds as shown in Table 2. In total, 300 performance graphs were plotted and their characteristics of changes in track irregularity were analyzed. Figures 1, 2 and 3 present three typical performance graphs, and Tables 4 to 9 list their data including inspection values $\left\{X\left(t_{i}\right)\right\}$ and maintenance $\operatorname{modes}\left\{M\left(t_{i}\right)\right\}$.

Table 4 Amplitude Series of Track Gauge at Mileage Point K423+725 in Jing-Hu Down-going Track

\begin{tabular}{|c|c|c|c|c|c|c|c|c|c|c|c|c|c|c|c|c|c|c|c|}
\hline$i$ & $t_{i}$ & $\begin{array}{l}S\left(t_{i}\right) \\
\text { (Day) }\end{array}$ & $\begin{array}{l}X\left(t_{i}\right) \\
(\mathrm{mm})\end{array}$ & $i$ & $t_{i}$ & $\begin{array}{l}S\left(t_{i}\right) \\
\text { (Day) }\end{array}$ & $\begin{array}{l}X\left(t_{i}\right) \\
(\mathrm{mm})\end{array}$ & $i$ & $t_{i}$ & $\begin{array}{l}S\left(t_{i}\right) \\
\text { (Day) }\end{array}$ & $\begin{array}{l}X\left(t_{i}\right) \\
(\mathrm{mm}) \\
\end{array}$ & $i$ & $t_{i}$ & $\begin{array}{l}S\left(t_{i}\right) \\
\text { (Day) }\end{array}$ & $\begin{array}{l}X\left(t_{i}\right) \\
(\mathrm{mm})\end{array}$ & $i$ & $t_{i}$ & $\begin{array}{l}S\left(t_{i}\right) \\
\text { (Day) }\end{array}$ & $\begin{array}{l}X\left(t_{i}\right) \\
(\mathrm{mm}) \\
\end{array}$ \\
\hline 1 & 20040902 & 0 & 2.14 & 11 & 20050420 & 230 & 3.02 & 21 & 20051011 & 404 & 6.35 & 31 & 20060309 & 553 & 9.68 & 41 & 20060814 & 67 & 3.73 \\
\hline 2 & 20040917 & 15 & 2.51 & 12 & 20050518 & 258 & 3.40 & 22 & 20051021 & 414 & 6.65 & 32 & 20060323 & 567 & 9.83 & 42 & 20060906 & 90 & 3.82 \\
\hline 3 & 20041011 & 39 & 2.31 & 13 & 20050527 & 267 & 3.37 & 23 & 20051029 & 422 & 6.95 & 33 & 20060409 & 584 & 11.23 & 43 & 20060914 & 98 & 4.50 \\
\hline 4 & 20041121 & 80 & 2.23 & 14 & 20050603 & 274 & 4.70 & 24 & 20051104 & 428 & 7.08 & 34 & 20060419 & 594 & 12.02 & 44 & 20061015 & 129 & 4.19 \\
\hline 5 & 20041212 & 101 & 2.01 & 15 & 20050616 & 287 & 4.14 & 25 & 20051116 & 440 & 7.34 & 35 & 20060514 & 619 & 13.22 & 45 & 20061109 & 154 & 4.58 \\
\hline 6 & 20041218 & 107 & 3.04 & 16 & 20050708 & 309 & 4.56 & 26 & 20051128 & 452 & 7.50 & 36 & 20060527 & 632 & 14.59 & 46 & 20061116 & 161 & 4.49 \\
\hline 7 & 20050221 & 172 & 2.21 & 17 & 20050720 & 321 & 5.79 & 27 & 20051130 & 454 & 7.54 & 37 & 20060608 & 0 & 15.46 & 47 & 20061203 & 178 & 5.94 \\
\hline 8 & 20050310 & 189 & 2.65 & 18 & 20050809 & 341 & 5.05 & 28 & 20051205 & 459 & 7.79 & 38 & 20060619 & 11 & 4.41 & & & & \\
\hline 9 & 20050318 & 197 & 2.90 & 19 & 20050821 & 353 & 5.13 & 29 & 20060109 & 494 & 8.27 & 39 & 20060710 & 32 & 4.12 & & & & \\
\hline 10 & 20050408 & 218 & 2.95 & 20 & 20050901 & 364 & 5.15 & 30 & 20060220 & 536 & 9.01 & 40 & 20060807 & 60 & 3.99 & & & & \\
\hline
\end{tabular}

Table 5 Amplitude Series of Track Right Surface at Mileage Point K669+350 in Jing-Hu Up-going Track

\begin{tabular}{|c|c|c|c|c|c|c|c|c|c|c|c|c|c|c|c|c|c|c|c|}
\hline$i$ & $t_{i}$ & $\begin{array}{l}S\left(t_{i}\right) \\
\text { (Day) }\end{array}$ & $\begin{array}{l}X\left(t_{i}\right) \\
(\mathrm{mm})\end{array}$ & $i$ & $t_{i}$ & $\begin{array}{l}S\left(t_{i}\right) \\
\text { (Day) }\end{array}$ & $\begin{array}{l}X\left(t_{i}\right) \\
(\mathrm{mm})\end{array}$ & $i$ & $t_{i}$ & $\begin{array}{l}S\left(t_{i}\right) \\
\text { (Day) }\end{array}$ & $\begin{array}{l}X\left(t_{i}\right) \\
(\mathrm{mm})\end{array}$ & $i$ & $t_{i}$ & $\begin{array}{l}S\left(t_{i}\right) \\
\text { (Day) }\end{array}$ & $\begin{array}{l}X\left(t_{i}\right) \\
(\mathrm{mm})\end{array}$ & $i$ & $t_{i}$ & $\begin{array}{l}S\left(t_{i}\right) \\
\text { (Day) }\end{array}$ & $\begin{array}{l}X\left(t_{i}\right) \\
(\mathrm{mm}) \\
\end{array}$ \\
\hline 1 & 20040918 & 0 & 6.37 & 11 & 20050519 & 245 & 7.55 & 21 & 20051020 & 397 & 8.60 & 31 & 20060518 & 607 & 10.95 & 41 & 20061023 & 765 & 13.11 \\
\hline 2 & 20041012 & 24 & 6.44 & 12 & 20050527 & 251 & 7.94 & 22 & 20051030 & 407 & 8.68 & 32 & 20060601 & 621 & 11.29 & 42 & 20061115 & 788 & 15.23 \\
\hline 3 & 20041122 & 65 & 5.97 & 13 & 20050617 & 272 & 7.86 & 23 & 20051110 & 418 & 8.00 & 33 & 20060618 & 638 & 11.21 & 43 & 20061123 & 796 & 16.13 \\
\hline 4 & 20041213 & 86 & 6.58 & 14 & 20050628 & 283 & 7.94 & 24 & 20051220 & 458 & 8.09 & 34 & 20060629 & 649 & 10.68 & 44 & 20061213 & 816 & 18.76 \\
\hline 5 & 20041219 & 92 & 6.58 & 15 & 20050727 & 312 & 7.83 & 25 & 20051230 & 468 & 8.03 & 35 & 20060723 & 673 & 11.12 & & & & \\
\hline 6 & 20050222 & 157 & 6.76 & 16 & 20050805 & 321 & 7.98 & 26 & 20060125 & 494 & 8.65 & 36 & 20060805 & 686 & 11.88 & & & & \\
\hline 7 & 20050311 & 174 & 6.97 & 17 & 20050812 & 328 & 7.92 & 27 & 20060213 & 513 & 8.65 & 37 & 20060817 & 698 & 11.21 & & & & \\
\hline
\end{tabular}




$\begin{array}{cccccccccccccccc}8 & 20050319 & 182 & 7.27 & 18 & 20050828 & 344 & 8.16 & 28 & 20060222 & 522 & 8.94 & 38 & 20060828 & 709 & 12.22 \\ 9 & 20050409 & 203 & 7.17 & 19 & 20050916 & 363 & 8.07 & 29 & 20060320 & 548 & 9.26 & 39 & 20060918 & 730 & 11.93 \\ 10 & 20050420 & 214 & 7.62 & 20 & 20050928 & 375 & 7.90 & 30 & 20060501 & 590 & 10.21 & 40 & 20061016 & 758 & 12.49\end{array}$

Table 6 Amplitude Series of Track Gauge at Mileage Point K423+606 in Jing-Hu Down-going Track

\begin{tabular}{|c|c|c|c|c|c|c|c|c|c|c|c|c|c|c|c|c|c|c|c|}
\hline$i$ & $t_{i}$ & $\begin{array}{l}S\left(t_{i}\right) \\
\text { (Day) }\end{array}$ & $\begin{array}{l}X\left(t_{i}\right) \\
(\mathrm{mm})\end{array}$ & $i$ & $t_{i}$ & $\begin{array}{l}S\left(t_{i}\right) \\
\text { (Day) }\end{array}$ & $\begin{array}{l}X\left(t_{i}\right) \\
(\mathrm{mm})\end{array}$ & $i$ & $t_{i}$ & $\begin{array}{l}S\left(t_{i}\right) \\
\text { (Day) }\end{array}$ & $\begin{array}{l}X\left(t_{i}\right) \\
(\mathrm{mm})\end{array}$ & $i$ & $t_{i}$ & $\begin{array}{l}S\left(t_{i}\right) \\
\text { (Day) }\end{array}$ & $\begin{array}{l}X\left(t_{i}\right) \\
(\mathrm{mm})\end{array}$ & $i$ & $t_{i}$ & $\begin{array}{l}S\left(t_{i}\right) \\
\text { (Day) }\end{array}$ & $\begin{array}{l}X\left(t_{i}\right) \\
(\mathrm{mm})\end{array}$ \\
\hline 1 & 20040902 & 0 & 3.00 & 11 & 20050420 & 230 & 4.95 & 21 & 20051011 & 404 & 7.33 & 31 & 20060309 & 553 & 9.43 & 41 & 20060814 & 7 & 1.70 \\
\hline 2 & 20040917 & 15 & 2.81 & 12 & 20050518 & 258 & 5.17 & 22 & 20051021 & 414 & 7.57 & 32 & 20060323 & 567 & 9.68 & 42 & 20060906 & 30 & 1.67 \\
\hline 3 & 20041011 & 39 & 3.33 & 13 & 20050527 & 267 & 5.24 & 23 & 20051029 & 422 & 7.81 & 33 & 20060409 & 584 & 9.89 & 43 & 20060914 & 38 & 2.81 \\
\hline 4 & 20041121 & 80 & 3.96 & 14 & 20050603 & 274 & 5.34 & 24 & 20051104 & 428 & 7.92 & 34 & 20060419 & 594 & 10.02 & 44 & & 69 & 3.07 \\
\hline 5 & 20041212 & 101 & 3.88 & 15 & 20050616 & 287 & 5.41 & 25 & 20051116 & 440 & 8.01 & 35 & & 619 & 11.15 & 45 & & 94 & 2.73 \\
\hline 6 & 20041218 & 107 & 3.36 & 16 & 20050708 & 309 & 5.76 & 26 & 20051128 & 452 & 8.33 & 36 & 20060527 & 632 & 11.93 & 46 & 2006 & 101 & 3.07 \\
\hline 7 & 20050221 & 172 & 3.72 & 17 & 20050720 & 321 & 5.97 & 27 & 20051130 & 454 & 8.29 & 37 & 200606 & 644 & 12.68 & 47 & 20061203 & 118 & 3.07 \\
\hline 8 & 20050310 & 189 & 3.91 & 18 & 20050809 & 341 & 6.23 & 28 & 20051205 & 459 & 8.37 & 38 & 20060619 & 655 & 13.50 & & & & \\
\hline 9 & 20050318 & 197 & 4.04 & 19 & 20050821 & 353 & 6.45 & 29 & 20060109 & 494 & 8.79 & 39 & 20060710 & 676 & 15.53 & & & & \\
\hline 10 & 20050408 & 218 & 4.52 & 20 & 20050901 & 364 & 6.98 & 30 & 20060220 & 536 & 9.21 & 40 & 20060807 & 0 & 17.89 & & & & \\
\hline
\end{tabular}

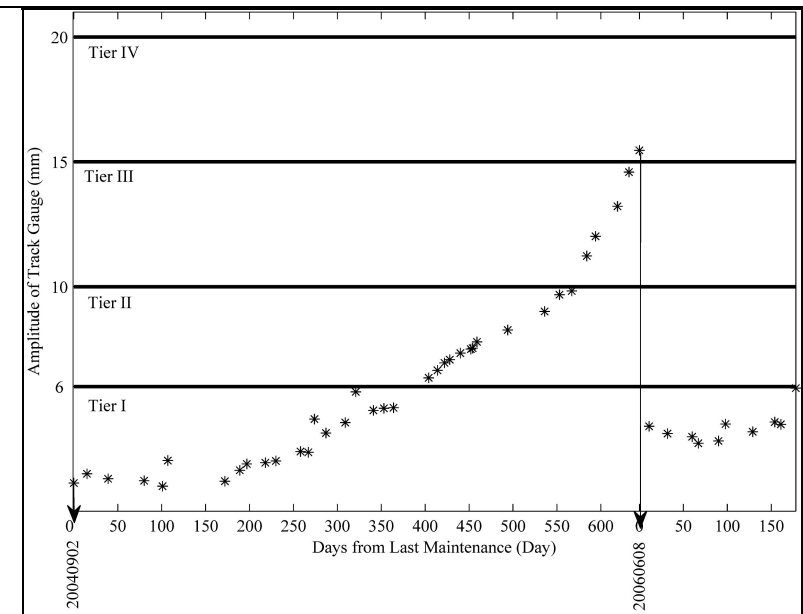

Figure 1 Actual Performance Graph of Track Gauge at Mileage Point K423+725 in Jing-Hu Down-going Track

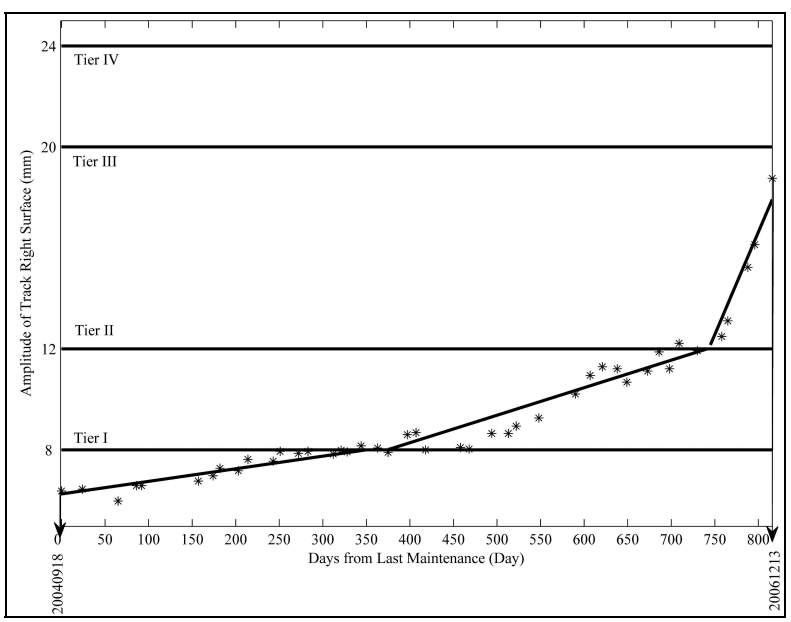

Figure 2 Actual Performance Graph of Right Track Surface at Mileage Point K669+350 in Jing-Hu Up-going Track

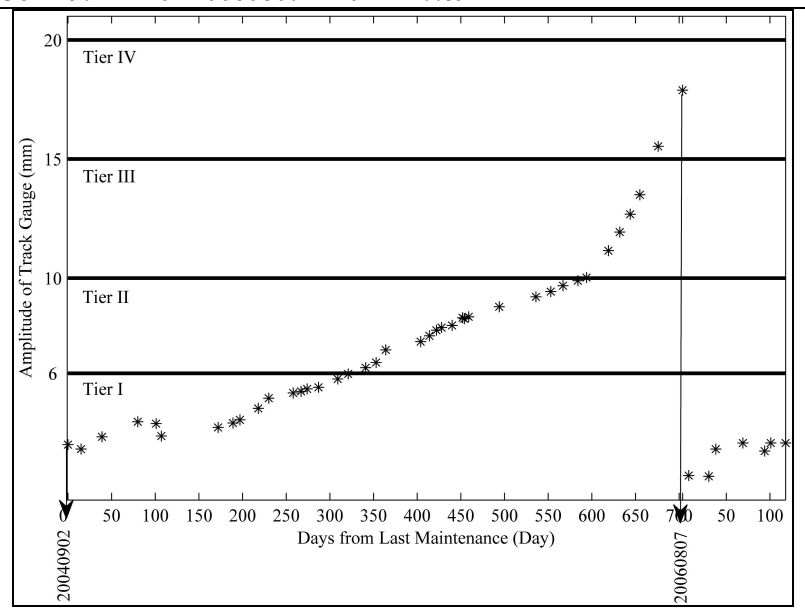

Figure 3 Actual Performance Graph of Track Gauge at Mileage Point K423+606 in Jing-Hu Down-going Track

Table 7 Time Series of Maintenance Time at Mileage Point K423+725 in Jing-Hu Down-going Track

\begin{tabular}{cccccc}
\hline$i$ & $t_{i}$ & $M\left(t_{i}\right)$ & $i$ & $t_{i}$ & $M\left(t_{i}\right)$ \\
\hline & & Routine & 2 & 20060608 & Temporary \\
1 & 20040902 & $\begin{array}{c}\text { supplementary } \\
\text { Maintenance }\end{array}$ & 2 & & repair \\
\hline
\end{tabular}

Table 8 Time Series of Maintenance Time at Mileage Point K669+350 in Jing-Hu Up-going Track

\begin{tabular}{cccccc}
\hline$i$ & $t_{i}$ & $M\left(t_{i}\right)$ & $i$ & $t_{i}$ & $M\left(t_{i}\right)$ \\
\hline 1 & 20040918 & $\begin{array}{c}\text { Routine } \\
\text { Maintenance }\end{array}$ & 2 & 20061213 & $\begin{array}{c}\text { Routine } \\
\text { maintenance }\end{array}$ \\
\hline
\end{tabular}


Table 9 Time Series of Maintenance Time at Mileage Point K423+606 in Jing-Hu Down-going Track

\begin{tabular}{cccccc}
\hline$i$ & $t_{i}$ & $M\left(t_{i}\right)$ & $i$ & $t_{i}$ & $M\left(t_{i}\right)$ \\
\hline 1 & 20040902 & $\begin{array}{c}\text { Routine } \\
\text { Maintenance }\end{array}$ & 2 & 20060807 & $\begin{array}{c}\text { Temporary } \\
\text { supplementary } \\
\text { repair }\end{array}$ \\
\hline
\end{tabular}

Figures 1, 2, and 3 show that after a maintenance treatment was completed on a track, the track deteriorated gradually and such deterioration was slower at first but faster later. Maintenances brought a track back into a good condition, from which the cyclic deterioration process restarts.

Based on analyzing 300 such performance curves developed in this study, the changes in local track irregularity demonstrate the following common characteristics:

(1) Periodic changes. There are cyclic deterioration processes of track state starting after a maintenance treatment.

(2) Exponential changes. After a maintenance treatment, a track section deteriorates in a nonlinear manner. Its condition becomes deteriorated slowly at beginning. Later on, the deterioration progresses in an exponential manner.

(3) Multi-stage changes. With the control thresholds for different track condition tiers as dividing point, track's condition changes at different rates over different tiers. The higher a control threshold is, the faster the track deteriorates.

\section{Multi-stage Linear Fitting Model of Railway \\ Track State Evolution}

To estimate the deterioration of track condition, a multi-stage framework based on the tier structure was proposed within which linear regression models were developed. In other words, different linear regression model was developed for different stages that are in corresponding to different tiers. It is a typical piecewise linear regression model approach.
Let $\mathrm{a}, \mathrm{b}, \mathrm{c}$, and $\mathrm{d}$ be the threshold for the four tiers of a certain irregularity, respectively. In the set $\{0, a, b, c, d, \infty\}$, the interval which is formed by every two adjacent elements is called a stage of change. We call the interval $[0, a)$ the first change stage, and the interval $[d, \infty)$ the last change stage. At each stage of change, we use the following linear equation $y=k \times t+b+\varepsilon$ (wherein: $t$ is the number of days from last maintenance) to describe the pattern of the track irregularity y over time $t$. The last term $\varepsilon$ denotes the errors in estimating the irregularity y. Figure 4 shows the multi-stage framework integrated with piecewise linear regression model. Note that such deterioration models are different for the tracks at different location. The performance curve shown in Figure 4 is only for location at k669+350 in Jing-Hu up-going track.

Assume that the measured track irregularities within one change cycle at a certain location and their inspection date are represented as $\left\{X\left(t_{i}\right)\right\}$ and $\left\{t_{1}, t_{2}, \ldots, t_{n}\right\}$, respectively, the arrangement of the measured irregularities and inspection time in different stages are presented in Table 10.

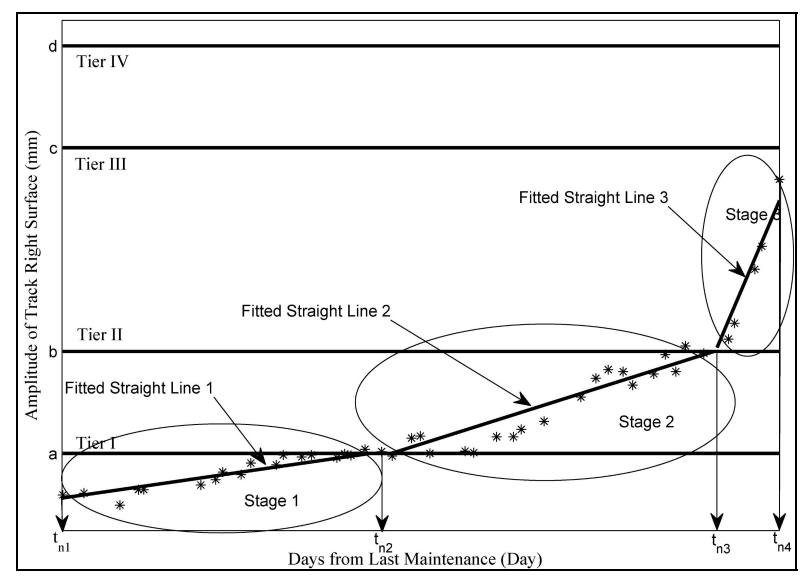

Figure 4 Steps to Establish the Multi-stage Linear Fitting Model

Table 10 Distribution of Amplitude and Inspection Time Series in Different Stages of Change

\begin{tabular}{cccc}
\hline Phase $i$ & Amplitude Interval & Distribution of Inspection Date $t_{i}$ & Distribution of Amplitude $X\left(t_{i}\right)$ \\
\hline 1 & {$[0, a)$} & $t_{n_{0}+1}, t_{n_{0}+2}, \ldots, t_{n_{1}}$, Wherein: $n_{0}=0$ & $X\left(t_{n_{0}+1}\right), X\left(t_{n_{0}+2}\right), \ldots, X\left(t_{n_{1}}\right)$ \\
2 & {$[a, b)$} & $t_{n_{1}+1}, t_{n_{1}+2}, \ldots, t_{n_{2}}$ & $X\left(t_{n_{1}+1}\right), X\left(t_{n_{1}+2}\right), \ldots, X\left(t_{n_{2}}\right)$ \\
3 & {$[b, c)$} & $t_{n_{2}+1}, t_{n_{2}+2}, \ldots, t_{n_{3}}$ & $X\left(t_{n_{2}+1}\right), X\left(t_{n_{2}+2}\right), \ldots, X\left(t_{n_{3}}\right)$ \\
\hline
\end{tabular}




\begin{tabular}{cccc}
\hline 4 & {$[c, d)$} & $t_{n_{3}+1}, t_{n_{3}+2}, \ldots, t_{n_{4}}$ & $X\left(t_{n_{3}+1}\right), X\left(t_{n_{3}+2}\right), \ldots, X\left(t_{n_{4}}\right)$ \\
5 & {$[d, \infty)$} & $t_{n_{4}+1}, t_{n_{4}+2}, \ldots, t_{n_{5}}$, Wherein: $n_{5}=n$ & $X\left(t_{n_{4}+1}\right), X\left(t_{n_{4}+2}\right), \ldots, X\left(t_{n_{5}}\right)$ \\
\hline
\end{tabular}

In the $i^{\text {th }}$ stage of change, we use Equation (1) and the data as denoted in Table 10 to fit a linear regression model:

$$
y_{i}(t)=a_{i}+b_{i} \times t \quad, \quad i=1,2,3,4,5
$$

where: the coefficients $\hat{a}_{i}$ and $\hat{b}_{i}$ are derived using the following formulas:

$$
\left.\begin{array}{c}
\hat{a}_{i}=\frac{\sum_{k=n_{i-1}+1}^{n_{i}} X\left(t_{k}\right) \sum_{k=n_{i-1}+1}^{n_{i}} t_{k}^{2}-\sum_{k=n_{i-1}+1}^{n_{i}} t_{k} \sum_{k=n_{i-1}+1}^{n_{i}} t_{k} X\left(t_{k}\right)}{\left(n_{i}-n_{i-1}\right) \sum_{k=n_{i-1}+1}^{n_{i}} t_{k}^{2}-\left(\sum_{k=t_{n_{i}+1}+1}^{n_{i}} t_{k}\right)^{2}} \\
\hat{b}_{i}=\frac{\left(n_{i}-n_{i-1}\right) \sum_{k=n_{i-1}+1}^{n_{i}} t_{k} X\left(t_{k}\right)-\sum_{k=n_{i-1}+1}^{n_{i}} t_{k} \sum_{k=n_{i-1}+1}^{n_{i}} X\left(t_{k}\right)}{\left(n_{i}-n_{i-1}\right) \sum_{k=n_{i-1}+1}^{n_{i}} t_{k}^{2}-\left(\sum_{k=t_{n-1}+1}^{n_{i}} t_{k}\right)^{2}}
\end{array}\right\}
$$

Based on the data from the location K669+350 on Jing-Hu up-going track, the piecewise linear models were calibrated and the results are shown in Table 11. Figure 5 provides a graphic presentation of the results.

Table 11 Multi-stage Linear Fitting Model for Changes in Right Track Surface at Mileage Point of K669+350 in Jing-Hu Up-Going Track

\begin{tabular}{cccc}
\hline & Interval of & & \\
Phase & Amplitude & Time Span & Fitting Model \\
$i$ & $(\mathrm{~mm})$ & & \\
\hline 1 & {$[0,8)$} & $20040918-20050828$ & $y_{1}(t)=6.25+0.0050 \times t$ \\
2 & {$[8,12)$} & $20050828-20061016$ & $y_{2}(t)=3.06+0.0122 \times t$ \\
3 & {$[12,20)$} & $20061016-20061213$ & $y_{3}(t)=44.94+0.0893 \times t$ \\
\hline
\end{tabular}

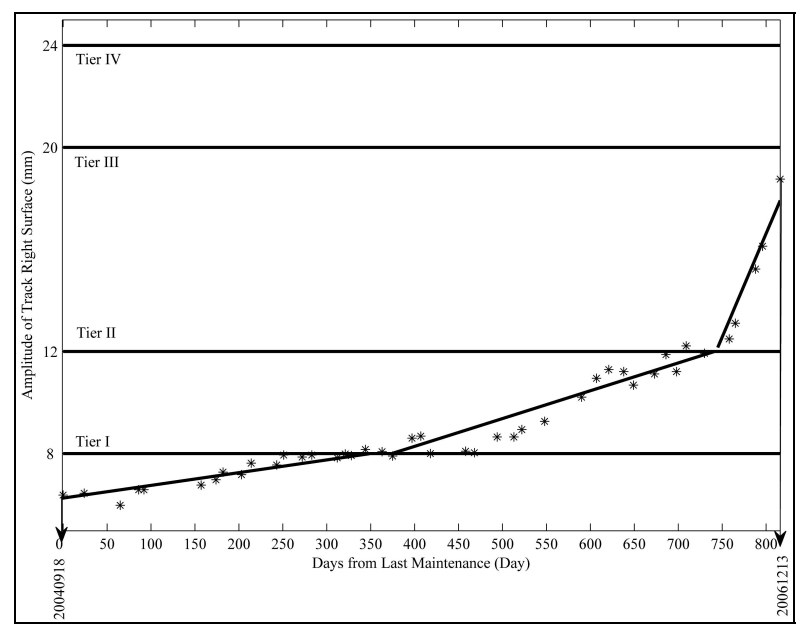

Figure 5 Fitting Results of Right Track Surface at Mileage Point of K669+350 in Jing-Hu Up-Going Track

Figure 5 and Table 11 show that the slope of the fitted line in the second change stage is greater than in the first one, and the slope in the third one is greater than in the first and second one. This means that after a same length time period the increase in right track surface within the second stage is normally greater than within the first one and the increase within the third stage is greater than within the first and second stage. This is a good case for the multi-stage characteristic of changes in right track surface.

On the other hand, if we just use one linear or none-linear equation to describe this change process, the errors in estimating right track surface are obviously greater than the ones resulted from our multi-stage linear model.

\section{Conclusions}

In this study, we developed a multi-stage framework integrated with linear regression model, i.e., piecewise linear regression model, using the waveform data generated by GJ-4 track geometry car. The model well presents the basic characteristics of track irregularities changing over time. The main conclusions of this paper are as follows: 
(1) Railway track irregularity shows the deterioration that is characterized as being cyclic, exponential, and multi-stage.

(2) With the control thresholds of irregularities for different tiers, track irregularity over these different tiers can be estimated by different linear regression models, each for different tiers.

Because of an insufficiency of the inspection data collected for this study, the impact of maintenance treatments on track's deterioration process was not investigated in this study. It will be studied with more data collected in future. In addition, it will also be looking into the ways to utilize the multi-stage linear regression model to plan and schedule required maintenance activities.

\section{References}

1. W.H. Wang, Q. Cao, K. Ikeuchi and H. Bubb, Reliability and Safety Analysis Methodology for Identification of Drivers' Erroneous Actions, International Journal of Automotive Technology. 11(6) (2010) 873-881.

2. Federal Railroad Administration Office of Safety Analysis - Train Accidents. Website: http://safetydata.fra.dot.gov/OfficeofSafety/publicsite/Quer y/inctally1.aspx. Retrieved on July 5, 2011.

3. S. Yoshihiko (eds.), New Railway Track Dynamics. (China Railway Press, Beijing, China, 2001), pp.98-194. In Simplified Chinese.

4. D. Bartram, M. Burrow and X. Yao, A Computational Intelligence Approach to Railway Track Intervention Planning, in Studies in Computational Intelligence (Springer, Germany, 2008), pp163-198.

5. E. Coenraad. Modern railway track, 2nd edn. (Delft University of Technology Pub. Service, The Netherlands, 2001), pp475-565, pp.349-406.

6. J. M. Sadeghi and H. Askarinejad, Development of Track Condition Assessment Model Based on Visual Inspection, in Structure and Infrastructure Engineering (Taylor \& Francis, England, 2009), pp1-11, iFirst.

7. L. M. Quiroga and E. Schnieder. A Heuristic Approach to Railway Track Maintenance Scheduling, in Proc. 12th International Conference on Computer System Design and Operation in Railways and other Transit Systems, eds. B. Ning and C.A. Brebbia (Beijing, China, 2010), pp.687-699.

8. CEN, prEN13848-1:2003 Railway Applications-Track-Track Geometry Quality- Part 1: Characterization of Track Geometry (CEN, Brussels, 2004).

9. X.M. Chen, Time-Frequency Analysis and Prediction Study on Track Irregularities (China Academy of Railway Science, Beijing, China, 2006). In Simplified Chinese.

10. J.J. Fan, Modern Railway Track, Second Edition. (China Railway Press, Beijing, China, 2004), pp36-53, pp221-267. In Simplified Chinese.
11. P. Veit, S. Marschnig, Sustainability in Track - A Precondition for High Speed Traffic, in Proceedings of the 2010 Joint Rail Conference ( Urbana, Illinois, USA, 2010), pp1-7.

12. Rail Accident Investigation Branch: Reports and bulletins. Website:

http://www.raib.gov.uk/publications/investigation_reports.c fm. Retrieved on June 8, 2011.

13. Y. Hao, Railway Engineering (China Railway Press, Beijing, China, 2002), In Simplified Chinese.

14. J. W. Hines and A. Usynin, Current Computational Trends in Equipment Prognostics, International Journal of Computational Intelligence Systems. 1(1) (2008) 94-102.

15. Y. Sato, S. Fujimori and A. Yoshimura, Real Time Digital Processing of Track Irregularities in Time of Speed-up on Tokaido and Sanyo Shinkansen, Quarterly Report of RTRI. 28(2-4) (1987) 42-47.

16. A. Furukawa and A. Yoshimura, Identification of Rolling Stock Lateral Dynamic Characteristics and Their Track Irregularity Maintenance Applications, Quarterly Report of RTRI. 46(1) (2005) 7-12.

17. J. P. Hyslip, Fractal Analysis of Track Geometry Data, Transportation Research Record. 1785 () (2002) 50-57.

18. J. Madejski, Autonomous Track Geometry Diagnostics System, Journal of Materials Processing Technology. 157-1580 (2004) 194-202.

19. P. G. Fausto, S. Felig and C. C. Javier, A Reliability Centered Approach to Remote Condition Monitoring. A Railway Points Case Study, Reliability Engineering and System Safety. 83(1) (2003) 33-40.

20. A. Kawaguchi, M. Miwa and K. Terada. Actual Data Analysis of Alignment Irregularity Growth and its Prediction Model, Quarterly Report of RTRI. 46(4) (2005) 262-268.

21. R.N. Iyengar and O.R. Jaiswal, Random Field Modeling of Railway Track Irregularities, Journal of Transportation Engineering. 121(4) (1995) 303-308.

22. R.M. Alfelor, G.A. Carr and M. Fateh, Track Degradation Assessment Using Gage Restraint Measurements, Transportation Research Record. 1742() (2001)68-77.

23. X.M. Chen, L. Wang, F.C. Yang, X.S. Cai and W.Q. Wu, Integrating Factor Method for Predicting the Developing Trend of Railway Track Irregularity, China Railway Science. 27(6) (2006) 27-31. In Simplified Chinese.

24. Infrastructure Inspection Center of China MOR, Track Inspection Techniques and Track Inspection Car Operation and Maintenance. (China Academy of Railway Science, Beijing, China, 2007). (Unpublished Resources). In Simplified Chinese.

25. X.T. Deng and Y.M. Ye, Principles and Applications of Quasi-high Speed Track Inspection Car. (China Railway Press. Beijing, China, 2004). In Simplified Chinese.

26. Ministry of Railways of the People's Republic of China, Regulations on Railway Line Maintenance. (China Railway Press. Beijing, China, 2006). In Simplified Chinese. 


\section{Acknowledgments}

This Research was fully sponsored by Ministry of Railways of the People's Republic of China Technology R\&D Program (No.2010G006-D), State Key Laboratory of Rail Traffic Control and Safety of Beijing Jiaotong University of China (No. SKL2008K005), and National Key Technology R\&D Program (2009BAG12A10). 